\title{
The Drosophila su(Hw) gene, which controls the phenotypic effect of the gypsy transposable element, encodes a putative DNA-binding protein
}

\author{
Susan M. Parkhurst, ${ }^{1,4}$ Douglas A. Harrison, ${ }^{1}$ Mary P. Remington, ${ }^{1}$ Carl Spana, ${ }^{1}$ Richard L. Kelley, ${ }^{2,5}$ \\ Robert S. Coyne, ${ }^{3,6}$ and Victor G. Corces ${ }^{1}$ \\ ${ }^{1}$ Department of Biology, The Johns Hopkins University, Baltimore, Maryland 21218 USA; ${ }^{2}$ Department of Embryology, \\ Carnegie Institute of Washington, Baltimore, Maryland 21210 USA; ${ }^{3}$ Department of Biochemistry and Molecular Biology, \\ Harvard University, Cambridge, Massachusetts 02138 USA
}

Homozygous mutations at the suppressor of Hairy-wing $[\mathrm{su}(\mathrm{Hw})]$ locus reverse the phenotype of gypsy-induced alleles in a number of genes located throughout the Drosophila genome. To understand the molecular basis of this phenomenon, the $s u(\mathrm{Hw})$ locus was isolated by chromosomal walking from a cloned homeo-box-containing sequence. The exact location of the gene was determined by Southern analysis of the DNA alterations associated with several $s u(H w)$ alleles. A 9.5-kb KpnI-SaII fragment, where all the DNA changes associated with $s u(H w)$ mutations were mapped, was able to rescue the $s u(H w)$ mutant phenotype after P-elementmediated germ-line transformation. This DNA fragment encodes a 3.3-kb RNA that is expressed in all stages of Drosophila development; the size or abundance of this RNA is affected in several $s u(H w)$ alleles tested. This transcript encodes a protein that contains a highly acidic region and 12 repeats of the ' $\mathrm{Zn}$ finger' domain characteristic of some DNA-binding and transcription-activating proteins, supporting the hypothesis that the $s u(H w)$ locus might encode a transcription factor that plays a role in the expression of the gypsy element.

[Key Words: Transposable element; suppression; transcriptional control; regulatory factor]

Received June 2, 1988; revised version accepted August 1, 1988.

Some transposable elements affect the genes they mutate by bringing their expression under the control of a second unlinked locus that is termed a modifier. The modifier gene is referred to as an enhancer or a suppressor locus, depending on the type of effect exerted by mutations in this gene on the phenotype of the transposable element-induced mutation. This type of phenomenon has been documented extensively in yeast and Drosophila (for reviews, see Roeder and Fink 1983; Rubin 1983; Kubli 1986; Parkhurst and Corces 1986b; Rutledge et al. 1988).

When the Ty transposable element of yeast inserts in the 5'-noncoding region of the HIS4 and LYS2 genes, it causes a mutant phenotype that can be reversed by second-site mutations at a variety of SPT loci (Winston et al. 1984a,b). The Ty-induced mutant phenotype might be due to the presence of transcription signals on the Ty element that interfere with the transcription of adjacent genes. The various $s p t$ mutations described probably

Present addresses: ${ }^{4}$ ICRF Developmental Biology Unit, Zoology Building, University of Oxford, South Parks Road, Oxford OX1 3PS, UK; ${ }^{5}$ Department of Zoology, University of Texas, Austin, Texas 78712 USA; ${ }^{6}$ Department of Cellular and Developmental Biology, Harvard University, Cambridge, Massachusetts 02138 USA. differ in the mechanism by which they reverse the mutant phenotype. For example, spt 3 , spt 7 , and spt 8 suppress mutations caused by the insertion of complete Ty elements or the long terminal repeats (called $\delta$ sequences) by abolishing transcription from the normal $\mathrm{Ty}$ promoter (Winston et al. 1984b, 1987). In contrast, spt4, spt5, and spt6 mutations are strong suppressors of solo $\delta$ insertion mutations but have little effect on Ty-induced mutations and do not affect the transcription of this element (Clark-Adams and Winston 1987). A third class of suppressor genes, represented by $S P T 13$ and $S P T 14$, suppress the phenotype of complete Ty insertion mutations, but not of solo $\delta$ insertion mutations, as a result of increased levels of transcription of the adjacent gene (Fassler and Winston 1988).

In Drosophila, several suppressor and enhancer mutations have been described that exert an effect on spontaneous mutant alleles in a transposable element-specific fashion, although the molecular mechanisms of these phenomena are poorly understood. Mutations at the suppressor of Hairy-wing [su(Hw), 3-54.8] locus reverse the phenotype of at least 15 gypsy-induced mutations at 11 different loci (Modolell et al. 1983; Parkhurst and Corces 1986b); suppressor of white-apricot $\left[s u\left(w^{a}\right), 1-0.1\right]$ 
partially restores the wild-type eye color of the copia-induced allele white-apricot $\left(w^{a}\right)$ (Levis et al. 1984; Zachar et al. 1985; Mount et al. 1988); mutations at suppressor of sable [su(s), 1-0] reverse the phenotype of spontaneous alleles at several loci caused by the insertion of the 412 retrotransposon (Chang et al. 1986; Searles and Voelker 1986). Additional interactions between some of the mutant alleles and their modifier loci can also take place (Rutledge et al. 1988). Mutations at the suppressor of forked [su(f), 1-65.9] locus can revert the phenotype of the same forked (f, 1-56.7) (Green 1955) and lozenge (lz, 1-27.7) (Snyder and Smith 1976) alleles suppressed by $s u(H w)$, but enhance the phenotype of $w^{a}$ (Green 1959) and $l z^{37}$ (Schalet 1970). The molecular bases of the transposable element-mediated interactions between the modifier loci and the mutant genes they affect are being studied using models such as the copia-induced $w^{a}$ and gypsy-induced yellow $\left(y^{2}\right)$ alleles. The copia element is inserted in an intron of the white gene in $w^{a}$ (Levis et al. 1984), and the mutagenic effect of this transposon may be due to its interference with proper splicing of the white RNA. This explanation is supported by recent findings indicating that $s u\left(w^{a}\right)$ encodes a protein involved in regulation of splicing (Chou et al. 1987; Zachar et al. 1987), although additional effects of the copia element on the developmental expression of white RNA cannot be discarded (Zachar et al. 1985; Mount et al. 1988). The effect of the gypsy element on the expression of the yellow locus in the $y^{2}$ allele seems to be caused via a different mechanism, as this mutation is due to the insertion of gypsy in the $5^{\prime}$ region of the gene, at -700 bp from the start of transcription (Chia et al. 1986; Geyer et al. 1986; Parkhurst and Corces 1986a). The adult tissue-specific phenotype in these mutant flies might be due to the gypsy-mediated interaction of the $s u(H w)$-encoded protein with transcriptional enhancer elements that are located upstream of the gypsy insertion point and control the expression of the yellow gene in the particular tissues that show a mutant phenotype (Geyer and Corces 1987; Geyer et al. 1988).

To further our understanding of the molecular mechanisms by which mutations at the $s u(\mathrm{Hw})$ locus reverse the phenotype of gypsy-induced alleles, we have cloned and characterized this gene. Here we present evidence suggesting that $\mathrm{su}(\mathrm{Hw})$ encodes a DNA-binding protein, supporting the hypothesis that this protein might interact with the gypsy element to control its transcription and, as a consequence, its mutagenic effect.

\section{Results}

\section{Molecular mapping of chromosomal deficiencies} associated with $\mathrm{su}(\mathrm{Hw})$

The $\operatorname{su}(\mathrm{Hw})$ locus maps on the third chromosome at $54.8 \mathrm{cM}$, in close proximity to the red (red, 3-53.6) locus (Lindsley and Grell 1968). The phenotype of these two mutations, in addition to trithorax (trx, 3-54.2), is uncovered by two small cytologically visible deficiencies designated $D f(3 R)$ red $^{P 52}$ and $D f(3 R)$ red $^{P 93}$ (Lewis 1981).
The localization of $s u(H w)$ within the DNA deleted in these two deficiencies allows the mapping of this gene to the $88 \mathrm{BC}$ region (Fig. 1A). As a first step to initiate a chromosomal walk to the $s u(\mathrm{Hw})$ locus, we determined the chromosomal location of a homeo-box-containing clone, known to map to the $88 \mathrm{BC}$ region (M. Levine, pers. comm.), with respect to the breakpoints of the two deficiencies mentioned above. A $\lambda$ clone containing this sequence ( $\lambda \mathrm{S} 63$ ) was hybridized to Drosophila polytene chromosomes obtained from larvae of the genotypes $D f(3 R)$ red $^{P 52} / D f(3 R) 293^{\gamma 5}$ and $D f(3 R)$ red $^{P 93} / D f(3 R) 293^{\text {r5 }}$. The presence of $D f(3 R) 293^{\gamma 5}$, which deletes the $87 \mathrm{E}-88 \mathrm{~A}$ region (Fig. 1A), results in asynapsis of the chromosomes in this area and facilitates the identification of the bands (R. Kelley and A. Spradling, in prep.). The clone $\lambda S 63$ hybridized only to the chromosome containing $D f(3 R) 293^{\gamma 5}$ in the $D f(3 R)$ red $^{p 93} / D f(3 R)^{\gamma 5}$ stock (Fig. 1B) and to both chromosomes in the $D f(3 R) r_{\text {red }}{ }^{\text {52/ }}$ $D f(3 R) 293^{\gamma 5}$ stock (data not shown). These results suggest that sequences contained in this $\lambda$ clone are deleted in $D f(3 R)$ red $^{P 93}$ but not in $D f(3 R)$ red $^{P 52}$ or $D f(3 R) 293^{\text {y5 }}$.

$\lambda S 63$ was then used to probe a wild-type Canton S library, and $\lambda$ clones extending in both directions, designated $\lambda \mathrm{R} 9$ and $\lambda \mathrm{L} 11$, were isolated (Fig. 2A). The end restriction fragments from these clones were used as hybridization probes to further the chromosomal walk, and clones $\lambda 3 \mathrm{R} 3$ and $\lambda 3 \mathrm{~L} 2$ were obtained. The different $\lambda$ clones were used as probes to carry out in situ hybridizations to polytene chromosomes from the $D f(3 R)$ red $^{P 93} /$ $D f(3 R) 293^{\gamma}$ stock. Clones $\lambda \mathrm{R} 9$ and $\lambda 3 \mathrm{R} 3$ hybridized only to the $D f(3 R) 293^{\gamma 5}$ chromosome (data not shown), indicating that DNA sequences contained in these clones were deleted in $D f(3 R)$ red $^{\text {P93 }}$; whereas clone $\lambda \mathrm{L} 11$ hybridized to both chromosomes (Fig. 1C). Therefore, sequences located in this clone are found outside of the deleted region. These results indicate that clone $\lambda L 11$ overlaps with the distal breakpoint of $D f(3 R)$ red $^{p 93}$, whereas clones $\lambda R 9$ and $\lambda 3 R 3$ are located closer to the red locus and the centromere; therefore, they specify the direction of the location of the $s u(H w)$ locus for the chromosomal walk to proceed. The exact position of the distal breakpoint in $D f(3 R)$ red $^{p 93}$ was located to a 1.8 -kb EcoRI fragment using Southern blots (Fig. 2A and data not shown). The same type of strategy, using in situ hybridization of various $\lambda$ clones to polytene chromosomes of the stock $D f(3 R)$ red $^{P 52} / D f(3 R) 293^{\gamma 5}$, was used to map approximately DNA sequences deleted in $D f(3 R)$ red $^{\text {P52 }}$; the distal breakpoint in this deficiency was localized to clone $\lambda 3 \mathrm{R} 3$ and to one of a series of small $(\sim 0.5 \mathrm{~kb})$ EcoRI fragments located in this clone (see Fig. 2A) by Southern analysis.

\section{Cloning of the su(Hw) locus by chromosomal walking}

To determine the exact location of the $s u(H w)$ locus, we made use of several spontaneous and $\gamma$-ray-induced alleles of this mutation. Spontaneous alleles usually are associated with the insertion of transposable elements, whereas $\gamma$-rays often result in the deletion of DNA sequences. Both types of alterations can be easily detected by Southern analysis. DNA was prepared from adult 


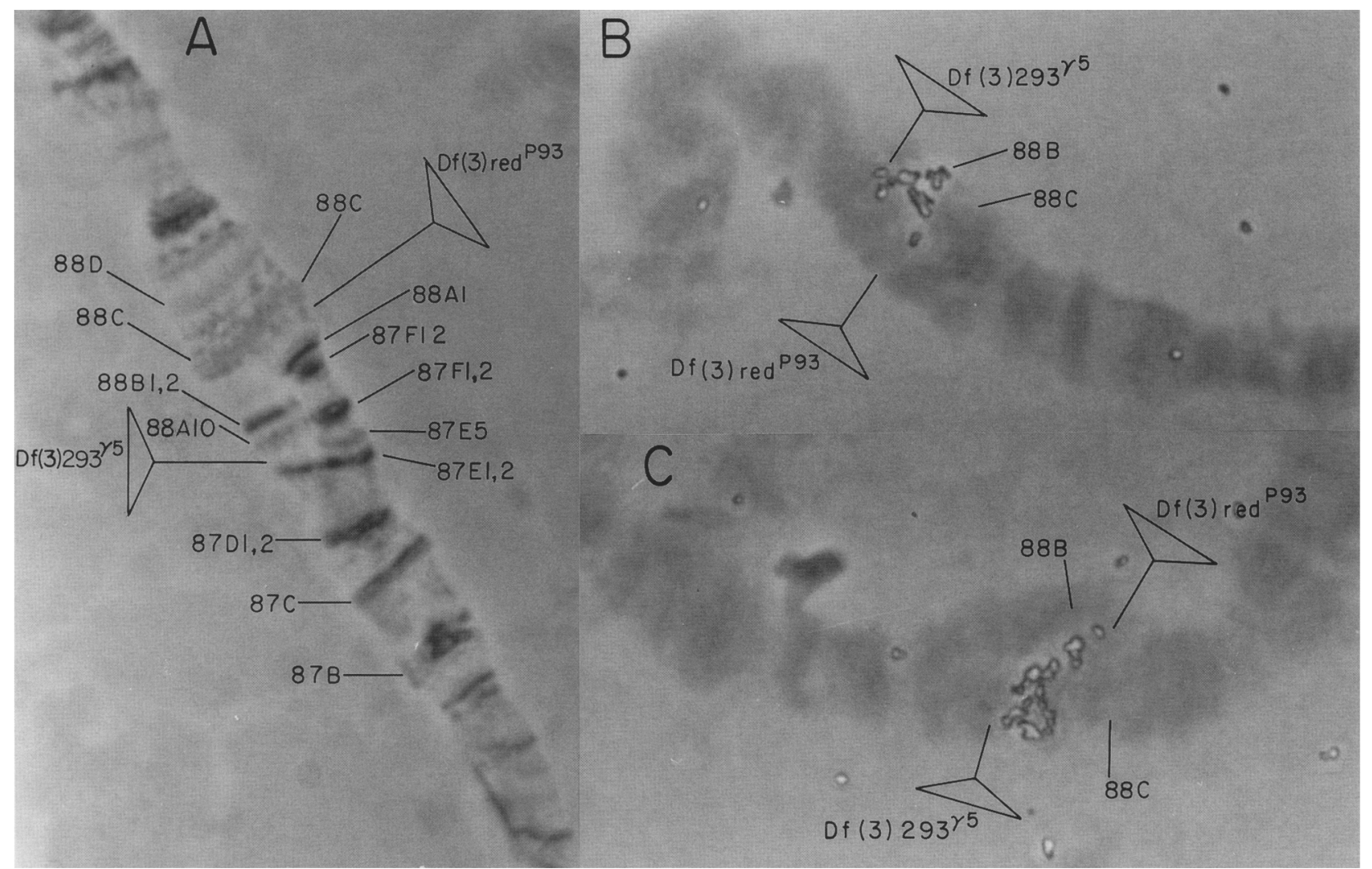

Figure 1. Cytological analysis of chromosomal deletions. $(A)$ Preparation of polytene chromosomes from the stock $D f(3 R)$ red $d^{p 93 /}$ $D f(3 R) 293^{\gamma 5}$. (B) In situ hybridization of ${ }^{3} \mathrm{H}$-labeled $\lambda$ S63 DNA to polytene chromosomes from $D f(3 R)$ red ${ }^{P 93} / \mathrm{Df}\left(3 \mathrm{R} / 293{ }^{\gamma 5}\right.$ larvae. (C) In situ hybridization of ${ }^{3} \mathrm{H}$-labeled $\lambda \mathrm{L} 11$ DNA to polytene chromosomes from the $D f(3 R)$ red $d^{P 93} / D f(3 R) 293^{\gamma 5}$ stock.

flies of different $\mathrm{su}(\mathrm{Hw})$ mutant stocks. The $\mathrm{su}(\mathrm{Hw})^{\mathrm{f3}}$ stock is fertile and homozygous viable, whereas $s u(H w)^{B}$ and $s u(H w)^{C}$ are sterile but viable as homozygotes. In addition, DNA was also made from transheterozygous adults of the stock $s u(H w)^{2} / s u(H w)^{f}$, due to the low viability of homozygous $\mathrm{su}(\mathrm{Hw})^{2}$ flies. The alleles $\mathrm{su}(\mathrm{HW})^{B}$ and $s u(H w)^{C}$ were induced by $\gamma$-ray irradiation, whereas the rest of the mutations analyzed arose spontaneously. Genomic DNA from these various stocks was digested with different restriction enzymes and subjected to Southern analysis; individual EcoRI fragments obtained from the different $\lambda$ clones of the chromosomal walk (Fig. 2A) were used as hybridization probes. No consistent changes in the restriction patterns obtained with EcoRI, BamHI, and XhoI were detected among Canton S, different $s u(H w)$ alleles, and their parental stocks when probes from $\lambda 3 \mathrm{~L} 2, \lambda \mathrm{L} 11, \lambda \mathrm{S} 63$, and $\lambda \mathrm{R} 9$ were used in the Southern analysis (data not shown). In marked contrast, DNA alterations were found associated with all four alleles examined when a 4.0-kb EcoRI fragment from $\lambda 3 \mathrm{R} 3$ (probe a, Fig. 2B) was used as a hybridization probe. Sequences contained in this clone are deleted in both $D f(3 R) r d^{P 52}$ and $D f(3 R) r^{2} d^{P 93}$. These alterations were not present in the parental stocks. Some selected examples of the Southern analyses carried out are shown in Figure 3. Figure 3A shows that the $s u(H w)^{j 3}$ allele contains an insertion of $0.7 \mathrm{~kb}$ into the $4.0-\mathrm{kb}$ HindIII fragment (probe b, Fig. 2B) when compared with the parental stock, $U b x^{r f g}$. Figure $3 \mathrm{~B}$ shows that the $s u(H w)^{2}$ allele is caused by an insertion of $1.3 \mathrm{~kb}$ into the $1.2 \mathrm{~kb}$ XbaI-ApaLI fragment (probe c, Fig. 2B). These results have now been confirmed by cloning and sequence analysis of DNA from the $s u(H w)^{\dagger 3}$ and $s u(H w)^{2}$ alleles (D.A. Harrison and V.G. Corces, in prep.). DNA from the $s u(H w)^{f}$ allele shows no alterations in the restriction pattern, suggesting that the phenotype is probably caused by a point mutation (see below for additional evidence). The $\gamma$-ray-induced alleles $s u(H w)^{B}$ and $s u(H w)^{C}$ are associated with small deletions, as the sizes of the HindIII restriction fragment (Fig. $3 \mathrm{C}$ ) are smaller than that of wild type. The approximate location of the molecular defects associated with these four alleles is indicated in Figure $2 \mathrm{~B}$ by horizontal lines spanning the affected DNA fragments. These results delimit the region where the $s u(H w)$ gene is expected to reside.

\section{Changes in RNA transcripts associated with $\mathrm{su}(\mathrm{Hw})$ alleles}

To localize further the exact position of the su( $\mathrm{Hw})$ locus, we determined the pattern of developmental transcription in the region where the different DNA abnormalities related to $s u(H w)$ had been mapped. RNA was prepared from larvae, pupae, and adults of wild-type and 

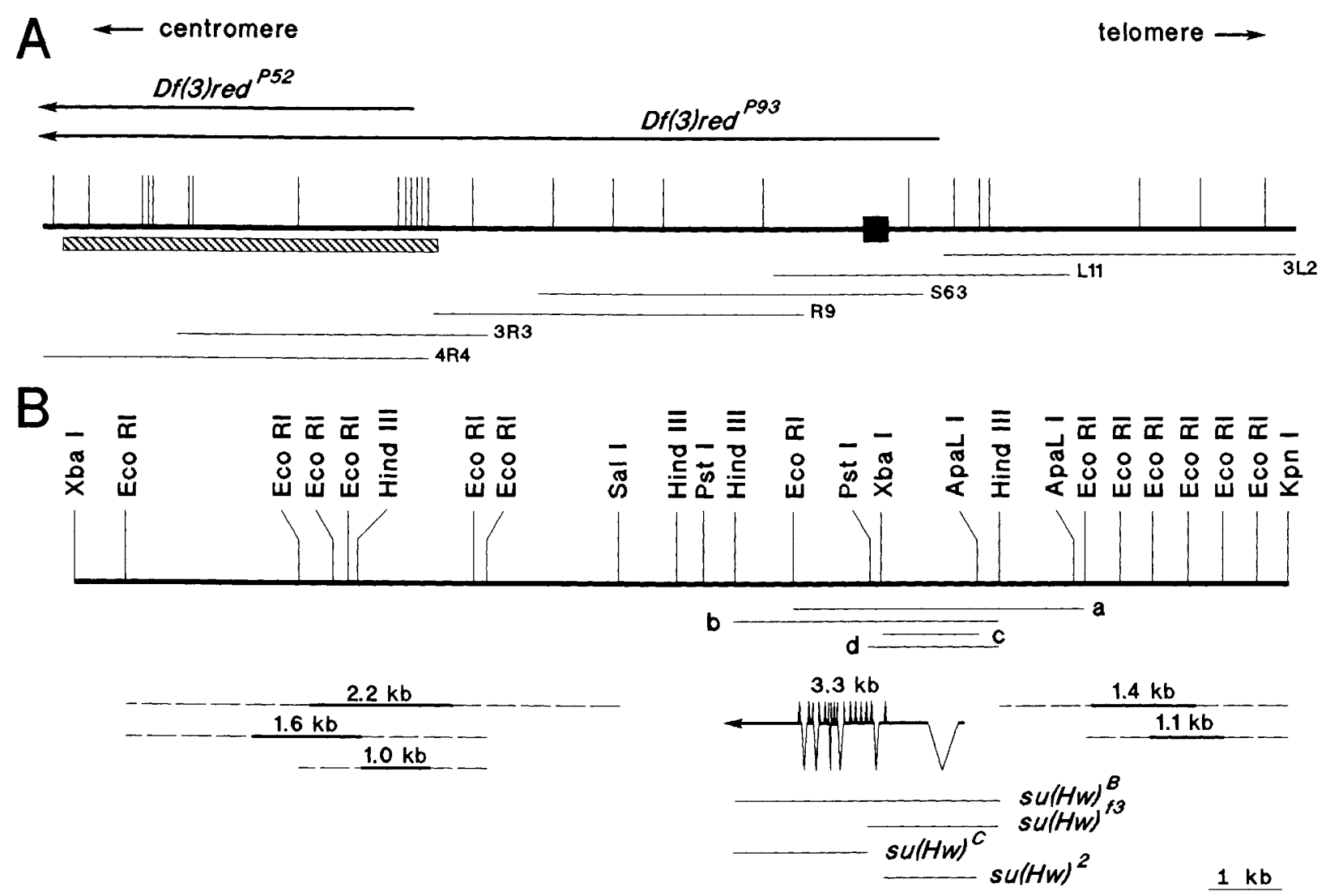

Figure 2. DNA structure of the $s u(\mathrm{Hw})$ locus and adjacent regions. $(A)$ Restriction map of the $88 \mathrm{BC}$ region covered by the chromosomal walk. Vertical lines denote EcoRI sites, and the black square indicates the location of the homeo box homology contained in the clone $\lambda S 63$ used to initiate the walk. The different clones isolated during this chromosomal walk are indicated at the bottom of $A$ by horizontal lines. The top of the $A$ shows the distal breakpoints of the deficiencies $D f(3) r e d^{P 93}$ and $D f(3)$ red $^{P 52}$. The region underlined by a crosshatched bar on the left side of the map is shown in detail in $B$. (B) Restriction map of the su(Hw) locus. Only some $P s t \mathrm{I}$ and ApaLI sites are indicated. Horizontal lines located immediately under the map show the location of various hybridization probes used in these studies. Also indicated is the location of the different transcripts detected in the region. The exon-intron structure of the $\mathrm{su}(\mathrm{Hw})$ gene is shown in detail, with the location of the different $\mathrm{Zn}$ finger domains indicated by vertical lines. The restriction fragments where the $s u(H w)^{f 3}, s u(H w)^{2}, s u(H w)^{B}$, and $s u(H w)^{C}$ alleles have been mapped are shown by horizontal lines at the bottom of $B$.

mutant stocks and subjected to Northern analysis using the entire $\lambda 3 \mathrm{R} 3$ clone (Fig. $2 \mathrm{~A}$ ) as a probe. This DNA hybridized to four different transcripts, $3.3,2.2,1.4$, and $1.1 \mathrm{~kb}$, on Northern blots containing poly $(\mathrm{A})^{+} \mathrm{RNA}$ from wild-type flies (Fig. 4). The approximate location of these four transcripts was mapped by using different EcoRI restriction fragments from the region as hybridization probes (data not shown). These results are summarized in Figure 2B by solid lines that denote the size of the RNAs, flanked by broken lines that indicate the limits of the region containing the different transcripts. The structure of the 3.3-kb RNA is indicated in more detail based on results discussed below. Also shown in Figure $2 \mathrm{~B}$ is the location of two additional transcripts, 1.6 and $1.0 \mathrm{~kb}$ in length, that were not contained in the $\lambda 3 \mathrm{R} 3$ clone used in the experiment described in Figure 4.

The same four transcripts detected in wild-type RNA preparations were also observed when RNA from the stock $s u(H w)^{7} / s u(H w)^{f}$ was analyzed (data not shown). Because $s u(H w)^{7}$ is caused by a large cytologically vis- ible deletion, the RNA detected in this sample must originate from the $s u(H w)^{f}$ chromosome, supporting the hypothesis that $s u(H w)^{f}$ is caused by a point mutation or a very small deletion that results in normal levels of transcription of a less functional product. The same pattern of RNAs was observed in $s u(H w)^{69 k} / s u(H w)^{f}$ flies, in agreement with the fact that no DNA aberrations could be associated with either of these mutations by Southern analysis (data not shown). In contrast, RNA from the $s u(H W)^{f 3}$ allele contains normal levels of the $2.2-, 1.4-$, and 1.1-kb transcripts, but very low levels of the 3.3-kb RNA, suggesting that this transcript is encoded by the su(Hw) locus (Fig. 4). This conclusion is supported by the fact that RNA from the $s u(H w)^{2} /$ $s u(H w)^{f}$ stock contains an additional 1.6-kb transcript that could arise as a consequence of premature termination of transcription of the 3.3-kb RNA, whereas the 1.4and 1.1-kb RNAs are present at normal levels (Fig. 4). The 1.6-kb RNA hybridizes to a HindIII-PstI fragment (probe d, Fig. 2B) that contains sequences specific for the 
su(Hw) locus encodes a $\mathrm{Zn}$ finger protein

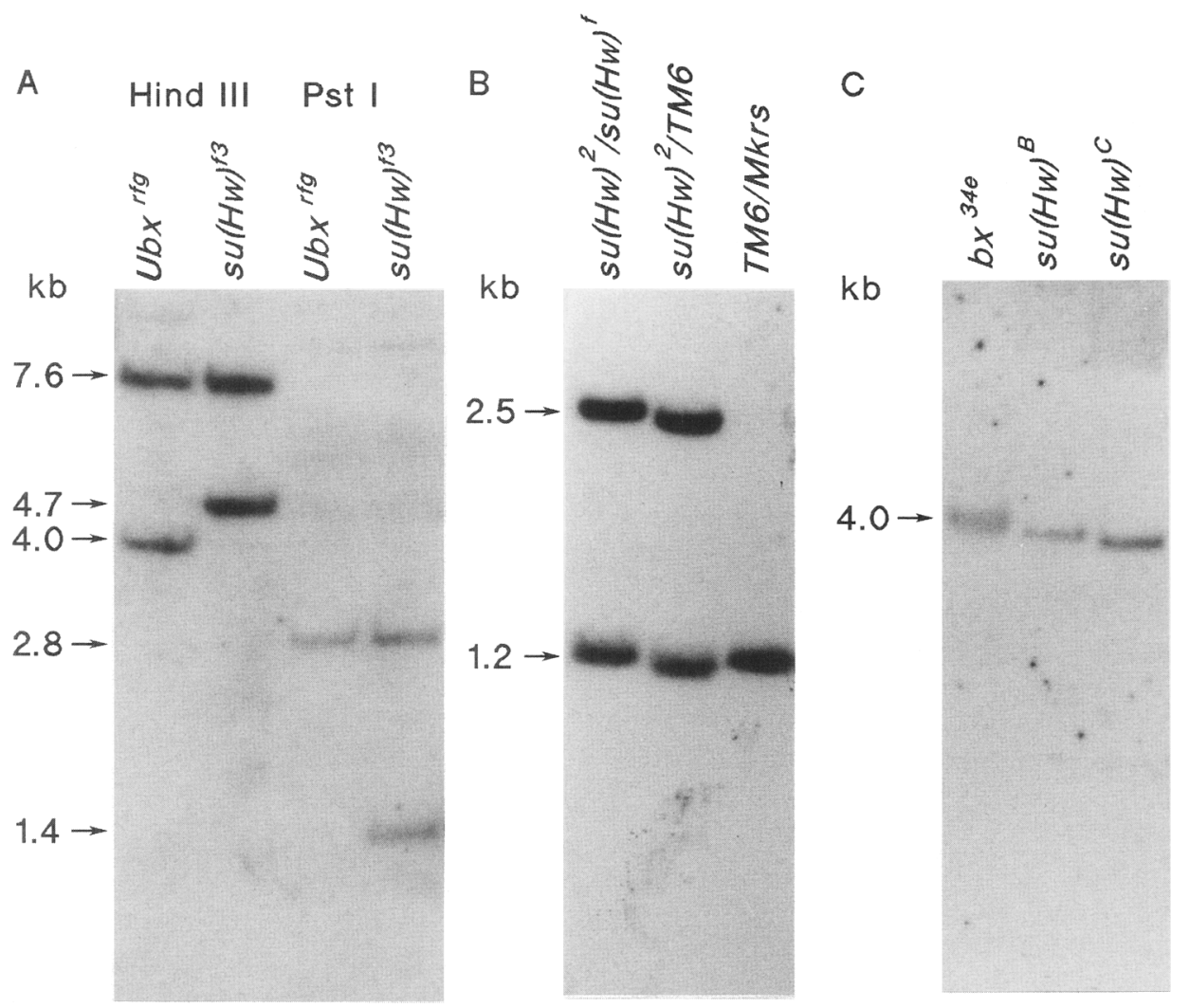

Figure 3. Southern analysis of $s u(H w)$ mutant alleles. Genomic DNA from wild-type and mutant stocks was digested with various restriction enzymes, electrophoresed on a $1 \%$ agarose gel, transferred to nitrocellulose paper, and hybridized with ${ }^{32} \mathrm{P}-1 \mathrm{abeled} \mathrm{DNA}$ containing the $s u(H w)$ locus. $(A)$ DNA from the $s u(H w)^{f 3}$ allele and its parental stock $U b x^{\text {ffg }}$ were digested with HindIII or PstI and subjected to Southern analysis using the 4.0-kb EcoRI fragment containing the $5^{\prime}$ region of the $s u(\mathrm{Hw})$ gene as a hybridization probe (probe a, Fig. 2B). (B) DNA was isolated from the stock $s u(H w)^{2} / s u(H w)^{f}$, the parental chromosome in which the $s u(H w)^{f}$ allele was induced (TM6), and a wild-type stock for the $s u(H w)$ locus (TM6/Mkrs). The DNA was digested with a mixture of XbaI and ApaLI and subjected to Southern analysis using the $1.2-\mathrm{kb} \mathrm{XbaI-ApaLI} \mathrm{fragment} \mathrm{as} \mathrm{a} \mathrm{probe} \mathrm{(probe} \mathrm{c,} \mathrm{Fig.} 2 \mathrm{~B}) .(\mathrm{C}) \mathrm{DNA}$ from the $s u(H w)^{B}$ and $s u(H w)^{C}$ mutant alleles and their parental stock $b x^{34 e}$ were digested with HindIII, and the Southern blot was hybridized with the 4.0-kb HindIII fragment (probe b, Fig. 2B).

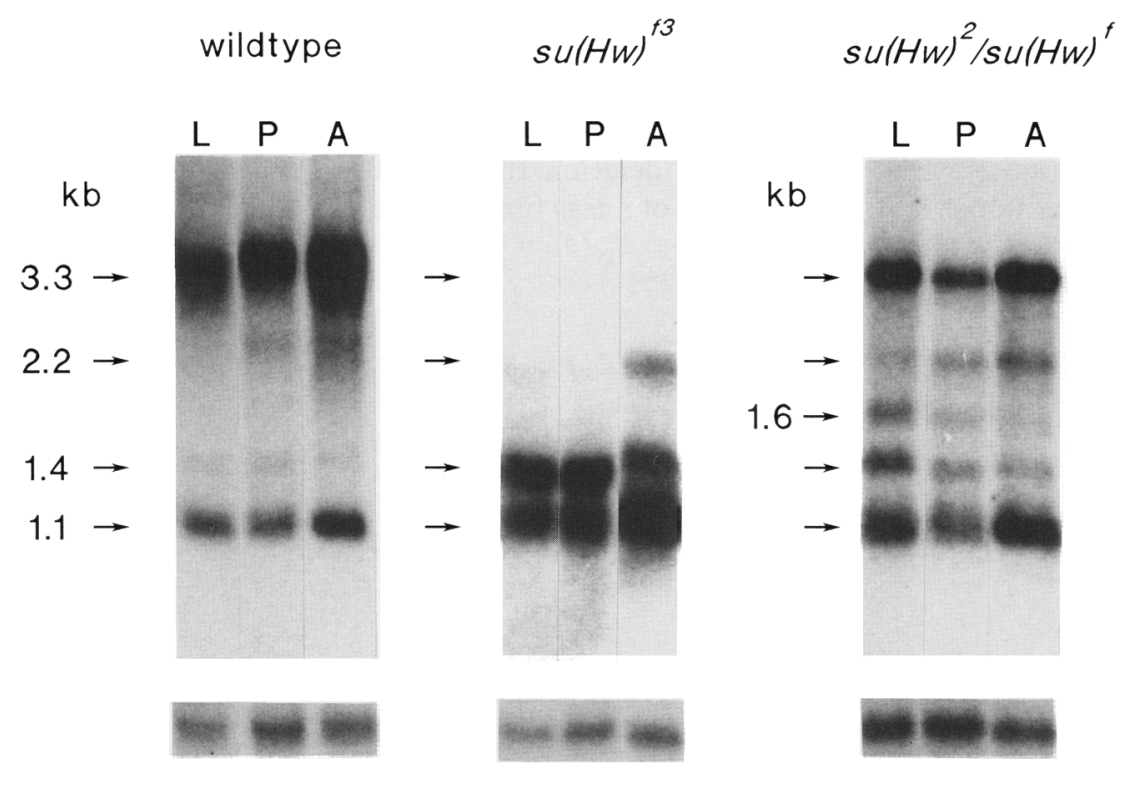

Figure 4. RNA analysis of wild-type and su(Hw) mutant alleles. Poly $(\mathrm{A})^{+}$RNA was isolated from larvae $(\mathrm{L})$, pupae $(\mathrm{P})$, and adults (A) of wild-type, su(Hw) ${ }^{f 3}$, and $\mathrm{su}(\mathrm{Hw})^{2} / \mathrm{su}(\mathrm{Hw})^{f}$ flies. Five micrograms were electrophoresed on a $1 \%$ agaroseformaldehyde gel, transferred to a nylon membrane, and hybridized with ${ }^{32} \mathrm{P}-\mathrm{la}-$ beled DNA from the clone $\lambda 3 \mathrm{R} 3$ (see Fig. 2A). (Bottom) The same blots hybridized with the Drosophila ras2 gene, which is expressed at approximately constant levels throughout development, as a control for the amount of RNA loaded in each lane. 
su(Hw) locus (data not shown). The 3.3-kb transcript present in RNA samples from $s u(H w)^{2} / s u(H w)^{f}$ flies presumably originates from the $s u(\mathrm{Hw})^{f}$ allele (see above).

The su(Hw) mutant phenotype can be rescued by $P$. element-mediated transformation

Confirmation of the precise location of the $s u(\mathrm{Hw})$ locus in a specific region was obtained by the ability of DNA fragments from this region to rescue the mutant phenotype of $s u(H w)$ flies. The 18-kb KpnI-XbaI and the 9.5$\mathrm{kb} K p n I-S a l$ fragments depicted in Figure 2B were cloned into the CaSpeR vector, which contains the Drosophila white gene as a marker for transformation (Pirrotta et al. 1985). Transformants were obtained using the stock, $D f(1) w, y^{2} s c^{1} w^{67 c 23(2)} \quad c t^{6} f^{1} ; s u(H w)^{69 k}$ e/TM6, $s u(H w)^{f}$ and identified on the basis of eye color. The presence of the transforming DNA was confirmed by Southern analysis (data not shown). One wild-type eye color transformant line was established containing each of the plasmids mentioned above. Both of these transformants were genotypically $y^{2} s c^{1} c t^{6} f^{1} ; s u(H w)^{69 k} /$ $s u(H w)^{f}$ but had yellow, scute, cut, and forked phenotypes. This conclusion indicates that the $s u(H w)$ phenotype was rescued by the injected plasmids, because the $s u(H w)$ mutation in the transformed flies was not able to reverse the gypsy-induced phenotype of the $y, s c, c t$, and $f$ mutations. In addition, the transforming DNA was also able to rescue the female sterility associated with $s u(H w)^{69 k}$. On the basis of this evidence, the $s u(H w)$ locus can be localized to the 9.5-kb KpnI-Sall fragment (Fig. 2B).

\section{Temporal and tissue-specific expression of the $\mathrm{su}(\mathrm{Hw})$ locus}

Several $s u(H w)$ alleles cause female sterility, suggesting that the product encoded by this locus might be necessary in the ovary during the development of the egg and should therefore be transcribed there. Poly $(A)^{+}$RNA was prepared from the ovaries of mature adult females obtained from Canton $\mathrm{S}$ and $\mathrm{su}(\mathrm{HW})^{f 3}$ stocks and subjected to Northern analysis using $\lambda 3 \mathrm{R} 3$ as hybridization probe. Figure 5A shows that ovaries from wild-type flies only express the $3.3-$ and $2.2-\mathrm{kb}$ RNAs and that the accumulation of the former transcript is severely affected in $s u(H w)^{f 3}$. A novel 4.0-kb RNA can also be detected in these mutant flies, presumably due to transcription through the DNA insert responsible for the mutation. A large transcript of similar size was also observed in RNA preparations from ovaries of $s u(H w)^{69 k} / s u(H w)^{f}$ females, although this aberrant RNA could not be seen in preparations from whole adult animals of the same stock (data not shown). Two additional 1.4- and 1.1-kb RNAs encoded within the $\lambda 3 \mathrm{R} 3$ clone and present in both wildtype and mutant flies could not be detected in the ovary. These results support the conclusion that the $3.3-\mathrm{kb}$ RNA is the only $s u(H w)$-encoded transcript.

To study the temporal expression of the su(Hw)encoded-transcript, we prepared poly(A) ${ }^{+}$RNA from different stages of Drosophila development, collecting samples at 24-hr intervals. These RNAs were subjected to Northern analysis using a $s u(H w)$ cDNA clone as hybridization probe. The result of this experiment is shown in Figure $5 \mathrm{~B}$ and indicates that the $s u(\mathrm{Hw})$ locus is expressed in all stages of Drosophila development, with slightly higher levels of accumulation in larvae and adults. Figure 5C shows the same filter probed with the Drosophila ras2 gene, which is expressed at approximately the same levels throughout the development of the fly (Mozer et al. 1985) and is used here as a measure of the amount of RNA loaded in the different lanes.

\section{The su(Hw)-encoded protein contains 12 copies of the ' $\mathrm{Zn}$ finger' motif}

The direction of transcription of the $s u(H w)$ RNA was determined by hybridizing single-stranded RNA probes specific for each DNA strand (Melton et al. 1984) to Northern blots containing poly $(A)+$ RNA from adult flies. Only one strand-specific probe hybridized to the RNA (data not shown), indicating that the direction of transcription is toward the centromere (Fig. 2B).

To determine the organization of the su(Hw) locus, we isolated two overlapping cDNA clones from an embryonic wild-type cDNA library (Poole et al. 1985). One of these clones, designated cDNA-1, corresponded to a complete copy of the transcribed region, whereas the second (cDNA-2) was missing $\sim 500$ bp from the $5^{\prime}$ region. Both genomic and cDNA clones were sequenced. Comparison of these two sequences shows that $\mathrm{su}(\mathrm{Hw})$ contains seven exons separated by six introns (Fig. 2B). All but the first of these introns are quite small, in the range of $50-60 \mathrm{bp}$. The complete sequence of the protein-coding region of the $s u(\mathrm{Hw})$ locus obtained from Canton $S$ is represented in Figure 6 , starting at the mRNA cap site. The predicted molecular weight is 109,000 daltons. A careful analysis of this sequence shows the presence of 12 repeats of the $\mathrm{Zn}$ finger motif, which is characteristic of some DNA-binding proteins and transcription factors (Klug and Rhodes 1987). These various finger domains are located in the central portion of the protein and arranged in several exons, and some of them are interrupted by introns. Figure 7 shows a comparison of the amino acid sequence of the different $\mathrm{Zn}$ fingers of the $s u(H w)$ protein and a consensus sequence derived from various Drosophila, Xenopus, and mammalian finger-containing protein (Berg 1988). The consensus structure of the $\mathrm{Zn}$ finger motif is Phe/Tyr Xaa Cys Xaa Xaa Cys Xaa Xaa Xaa Phe Xaa Xaa Xaa Xaa Xaa Leu Xaa Xaa His Xaa Xaa Xaa Xaa His. This structure is quite well conserved among the different $\mathrm{Zn}$ fingers found to date, although invariant residues present in the consensus sequence, such as Leu and Phe, are not found in some particular finger domains described in other proteins (e.g., Tautz et al. 1987); and the number of amino acids present between the two His residues is variable, ranging between 3 and 5 in different $Z n$ fingers. The amino acids conserved in the $s u(H w)$ protein with respect to the consensus are underlined in Figure 7, and it is apparent that the critical invariant residues are also 


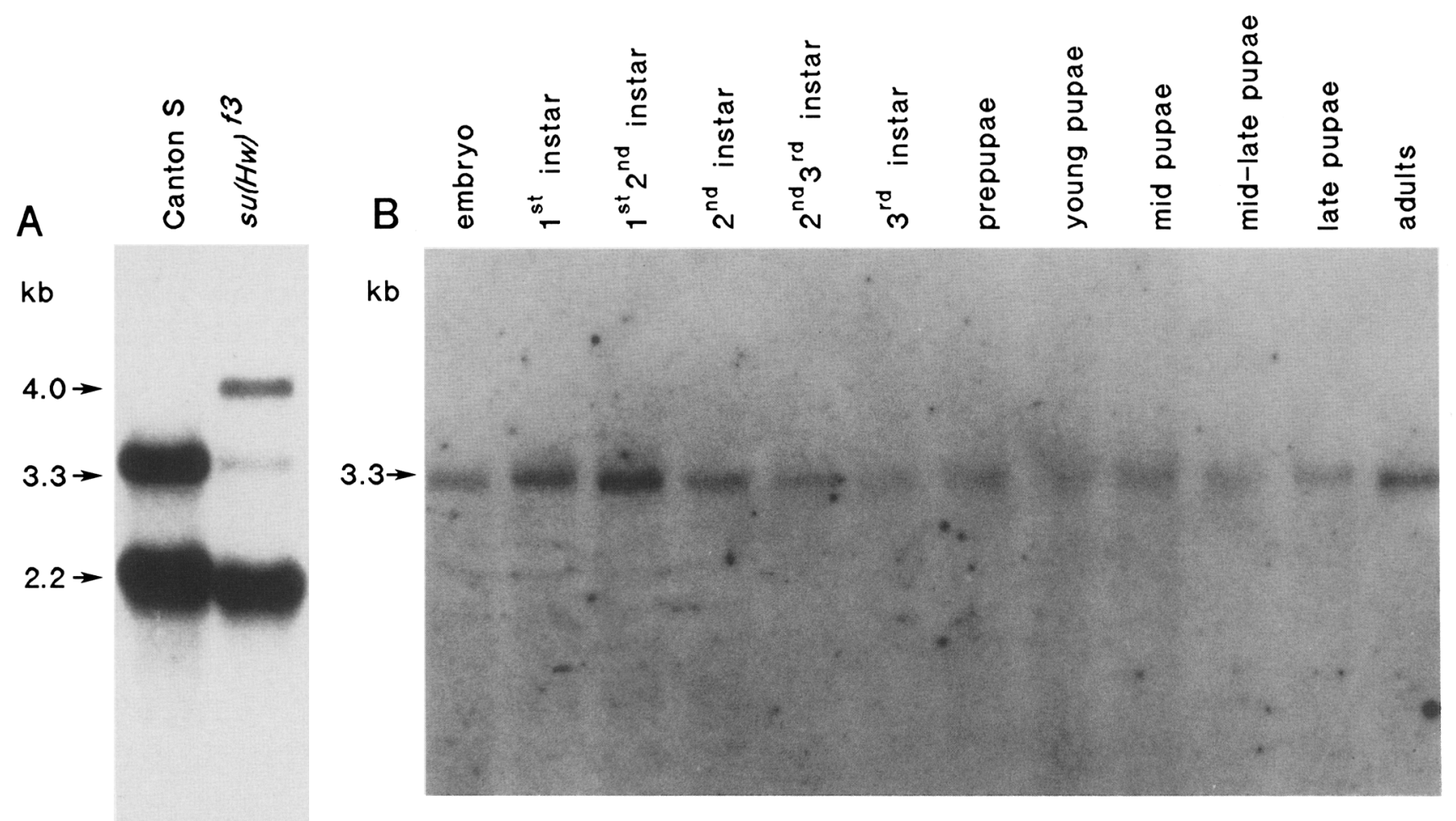

C

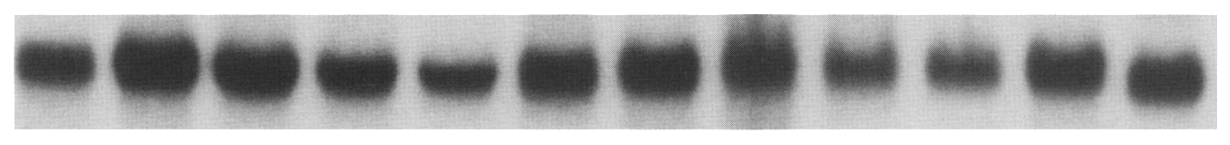

Figure 5. Developmental and tissue-specific transcription of the $s u(H w)$ gene. $(A)$ Five micrograms of poly $(A)^{+}$RNA, isolated from ovaries of mature females from Canton $\mathrm{S}$ and $\mathrm{su}(\mathrm{HW})^{f 3}$ stocks, was electrophoresed on a $1 \%$ agarose-formaldehyde gel, transferred to a nylon membrane, and hybridized with ${ }^{32}$ P-labeled $\lambda 3 \mathrm{R} 3$ (see Fig. $\left.2 \mathrm{~A}\right)$. $(B)$ Five micrograms of poly $(\mathrm{A})^{+}$RNA from different stages of Drosophila development was subjected to Northern analysis using a su(Hw) cDNA clone as hybridization probe. (C) The same filter shown in $B$ was hybridized with a clone containing the Drosophila ras2 gene.

maintained in most of the $s u(H w) \mathrm{Zn}$ fingers. Two exceptions are finger 2, which contains a Tyr instead of Leu, and finger 3, which contains a Leu instead of Phe. The same type of changes have been observed in the hunchback protein (Tautz et al. 1987). The terminal His has been replaced by a Cys in fingers 1 and 4 . This type of change does not affect the functionality of the finger, as both Cys and His are able to complex $\mathrm{Zn}$ and maintain the structure of the protein domain (Johnston 1987).

In addition to the $\mathrm{Zn}$ finger domains, a highly acidic region (48\% Asp and Glu) is present in the $s u(H W)$ protein between amino acids 154 and 202, immediately preceding the first $\mathrm{Zn}$ finger motif. These amino acids have been underlined in Figure 6. Similar acidic regions have been described in yeast transcriptional activator proteins such as GCN4 and GAL4 (Hope and Struhl 1986; Ma and Ptashne 1987).

\section{Discussion}

The $s u(H w)$ locus was isolated by chromosomal walking from a previously cloned sequence. The exact location of the $s u(H w)$ gene was mapped to a $9.5-\mathrm{kb} \mathrm{KpnI}-\mathrm{Sall}$ restriction fragment based on the ability of this DNA to rescue both the female sterility of the $s u(H w)^{69 k}$ allele and its capacity to reverse the phenotype of gypsy-induced mutations. The DNA sequences contained in the 9.5-kb fragment encode three different RNAs, 3.3, 1.4, and $1.1 \mathrm{~kb}$ long. The former transcript was determined to correspond to the $\mathrm{su}(\mathrm{Hw})$ locus on the basis of several criteria. This RNA is expressed in the ovaries of adult females as expected for a $s u(H w)$-encoded RNA because mutations at this locus cause female sterility, whereas the other two transcripts are not. In addition, DNA alterations associated with four different $s u(\mathrm{Hw})$ alleles mapped within the RNA-coding region of the $3.3-\mathrm{kb}$ transcript. Finally, $s u(H w)$ mutations affect the levels or size of the $3.3-\mathrm{kb}$ RNA but not the $1.4-$ or $1.1-\mathrm{kb}$ transcripts.

The $s u(H w)$ locus is expressed in all stages of Drosophila development and encodes a putative 109,000dalton protein that contains 12 repeats of the $\mathrm{Zn}$ finger 
Parkhurst et al.

ATACACAAACGCTTGTCGTGTTGGAATTTAAAGCATAAAATTAGgtaattg ...536 bp...2attgcagGCTGGTATCACCAAC ATG AGT GCC TCC AAG GAG GGC AAC AG

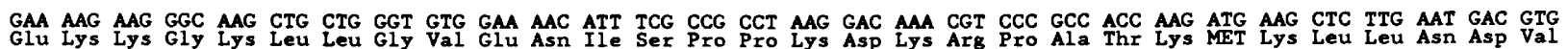
GGA GCT GGT GAG GAT TCG GAG GCA AGC ACT ACT ACT ACC ACA TCA AGA ACT CCC TCC AAC AAG CAG GAG AAG CGT GAC AGT GTC GCT GAA TCG CGC ATC AAA ATA CTC AAT GAA GAA ATA CTG GGC ACT CCG AAA ACT GAG AAA CGG GGC GCC ACA AAG AGC ACA GCT CCG GCT GCT TCC ACT GTG AAG ATT CTG AAC GA AAA AAG ACA CCC AGT GCT ACC GTG ACA GCC GTG GAA ACT ACC AAG ATC AAG ACG TCT CCC AGT AAA AGA
Thr Val Lys Ile Leu Asn Glu Lys Lys Thr Pro Ser Ala Thr Val Thr Ala Val Giu Thr Thr Lys Ile Lys Thr Ser Pro Ser Lys Arg AAG AAA ATG GAG CAC TAT GTA CTT CAG GCT GTG AAA TCA GAA AAT ACC AAG GCG GAC ACC ACG GTT ACC GTG GTC ACC GAA GAA GAT GAC
Lys Lys MET Glu Gis Tyr Val Leu G1n Ala Val Lys Ser Glu Asn Thr Lys Ala Asp Thr Thr Val Thr Val Val Thr Glu Glu Asp Asp ACC ATT GAT TTC ATT CTA GCG GAT GAT GAG GAA GTA GTT CCG GGC AGA ATA GAA AAT AAC AAC GGC CAG GAG ATC GTT GTC ACC GAG GAC
Thr Ile Asp Phe Ile Leu Ala Asp Asp Glu Glu Val Val Pro Gly Arg Ile Glu Asn Asn Asn Gly Gln Glu Ile Val Val Thr Glu Asp GAT GAG GAT CTA GGG GAG GAT GGT GAT GAG GAC GGT GAA GAC TCC TCA GGC AAG GGC AAC TCT AGC CAG ACA AAG ATC AAG GAG ATC GTG
Asp Glu Asp Leu Gly Glu Asp GIy Asp Glu Asp Gly Glu Asp Ser Ser Gly Lys Gly Asn Ser Ser Gln Thr Lys Ile Lys Glu Ile Val

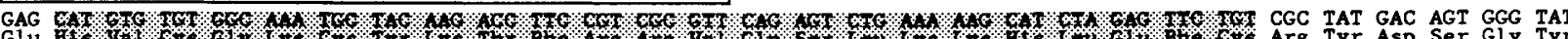
Glu Was CAT TTG CGC AAA GCC GAC ATG CTT AAG AAC CTG GAG AAG ATC GAG AAG GAT GCC GTG GTG ATG GAG AAG AAG GAC ATA TGC TTC TGC TGC
His Leu Arg Lys Ala Asp MET Leu Lys Asn Leu Glu Lys Ile Glu Lys Asp Ala Val Val MET Glu Lys Lys Asp Ile Cys Phe Cys Cys

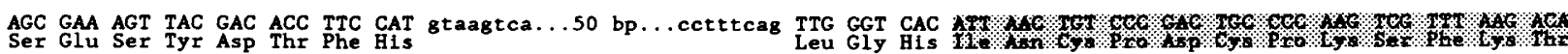

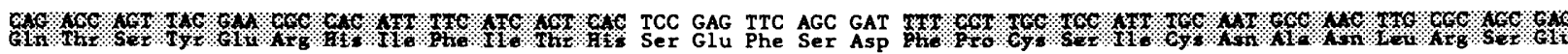

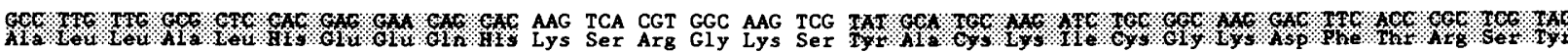

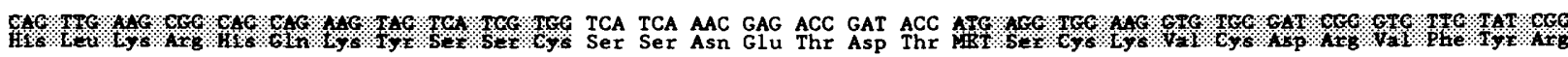

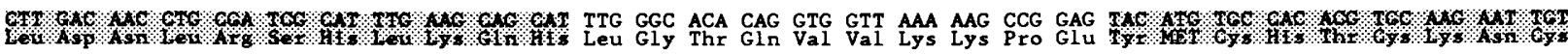

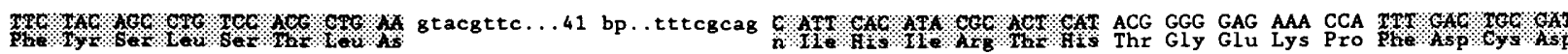

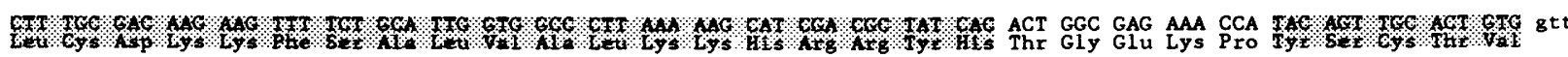

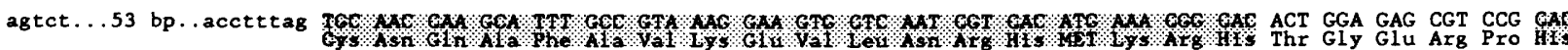

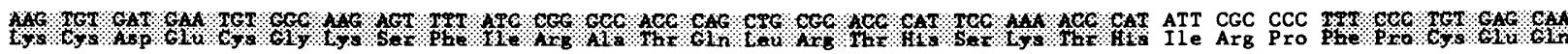

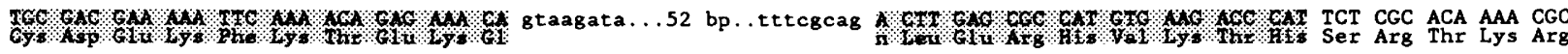

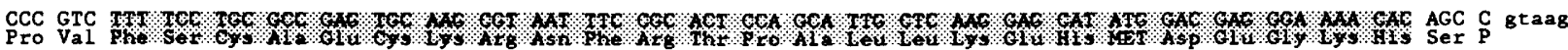

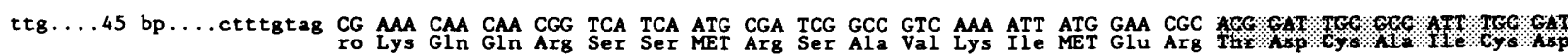

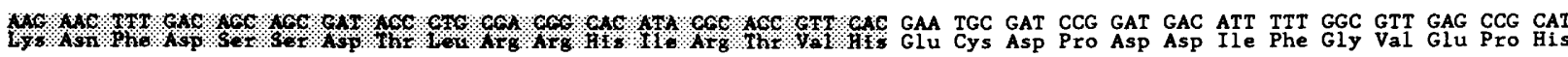
CCA TCA AAG CGT GCA AAG AAG GAC ATC GAA TCG GAG GAG GTT GTA CCA GTG GCG TTA AAC ACA TCA GCG GGC TCG TTA ATT TCC AGC CAA ACG GAC GGC AAT GAC GTT GTG GTG CGT GAA TTC CTC GTG GAC GAA GGC GAT GGC GCG GCC CAG ACC ATT ACA CTA GAA AAC GAA ACA TAC Thr Asp Gly Asn Asp Val Val Val Arg Glu phe Leu Val Asp Glu Gly Asp Gly Ala Ala Gln Thr Ile Thr Leu Glu Asn Glu Thr Tyr ACA ATT CTG CCC CTG GAC GGG GCC ATC GAG GGA GAG CAG CTG ACG GAT GAG GCT GGC GTT AAG CCC GAG GCG AAG AAG GAG GAG GCG CAG GTC TCG CCG GTG GTA AAG AAA GAG CAG CGT AAA TCC CTG GCC GCC AGT CTG GCC GCT GCC ATC GCA GAT AAT TTG GAA GAA TCA TGT AGC GAG GAT GAC TTC AGT GGC GAA ATT CTA ACT GAG GAG GAC ATA AAG CTC AAA GAG AAT GTG GGT AAA CTT ATT GAT ATG CTA GTG GAT CCA Glu Asp Asp phe Ser Gly Glu Ile Leu Thr Glu Glu Asp Ile Lys Leu Lys Glu Asn Val gly Lys Leu Ile Asp MET Leu Val Asp Pro CCG ATC CTA AAG AAA TAC GGC TGG CCC AAT GCC CCC GAG GAG ACG GTG CTC TGC AAA GTG ATC GAG AAC TGT GGC CAC GAC CTG ACT AAA
Pro Ile Leu Lys Lys Tyr Gly Trp Pro Asn Ala Pro Glu Glu Thr Val Leu Cys Lys Val Ile Glu Asn Cys Gly His Asp Leu Thr Lys GGT GGC GAA AAC TAC GCT GAG CTT GAC TAC GGT AGC CGC ATG CGA GAG TAC TGC AAA CTG CTC TTT ACC GTG GTC ATT CAC AAC GAT TCC ATC AAG TCG CTG CTC AAT AAT TTC CCC ATC GAC GAT GTG ATC GAA TAT GTA CTG GGA GAT GAG GAT CAG GAC GAA GGT GGA TTG GAC AAA
Ile Lys Ser Leu Leu Asn Asn Phe Pro Ile Asp Asp Val Ile Glu Ty Val Leu Gly Asp Glu Asp Gln Asp Glu GIy Gly Leu Asp Lys GAC AAT GAA GAC AAT GAG TCA CAT TCA GGT GAT GAA GAA GCG GTG TCG GTC ACA GGC GAA ACT AAA AAA AAT GAA ATC AAA GAG AAA CCC Asp Asn Glu Asp Asn Glu Ser bis Ser Gly Asp Glu Glu Ala Val Ser Val Thr Gly Glu Thr Lys Lys Asn Glu Ile Lys Glu Lys Pro GAA AAG AAG GAA GTT TCG GCG AAA TCT GAA AAG AAG GAG ATC GTG GGG AAA GCT GTG GAT AAG GAT AAC ACA GAG GAG GTG GTC CGG GAA
Glu Lys Lys Glu Val Ser Ala Lys Ser Glu Lys Lys Glu Ile Val Gly Lys Ala Val Asp Lys Asp Asn Thr Glu Glu Val Val Arg Glu AAT AAG AAA AAA CCT GTA GGC GAA CAA GAG AAA GCT TGA TTTTCCAGCCCTTCATGCATGCGTACAA TTACCGCACCAAAAACCATATTCTAGGAATTGATCGTTG 3827 CATTATGATTITTACAATGTATTTTTAAGATCGTTGGTTTTGGTACAAACACCAAGTGACCTTAAAAGAGAAACTTATCGTCTGTTGCTTGAATATTCAGACATCTTGCGCATTGACAA TAAGATCACCCAAAAACAAACCAACATATTACATATCAAAGATATTTTGATATTATTATATAGATTTTATATATTTTTGAATTGAATGATGTTACCAAGCAATATATGCATGGCTATTT

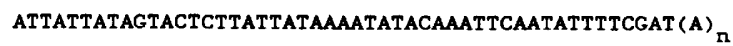

Figure 6. Sequence analysis of the $s u(H w)$ locus. The first nucleotide shown represents the start of transcription. Introns are denoted by lowercase letters, and only the first and last 8 bases are shown. Shaded areas indicate regions of homology to $\mathrm{Zn}$ finger domains. The acidic domain has been boxed, and Asp and Glu residues are underlined. 
$s u(\mathrm{Hw})$ locus encodes a $\mathrm{Zn}$ finger protein

\begin{abstract}
\#1 His Val Cys Gly Lys Cys Tyr Lys Thr Phe Arg Arg Val Gln Ser Leu Lys Lys His Leu Glu Phe Cys
\#2 Ile Asn Cys Pro Asp Cys Pro Lys Ser Phe Lys Thr Gln Thr Ser Tyr Glu Arg His Ile Phe Ile Thr His

\#3 Phe Pro cys Ser Ile cys Asn Ala Asn Leu Arg Ser glu Ala Leu Leu Ala Leu his Glu Glu Gln his

\#4 Iyr Ala Cys Lys Ile Cys Gly Lys Asp Phe Thr Arg Ser Tyr His Leu Lys Arg His Gln Lys Tyr Ser Ser Cys

\#5 Met Ser Cys Lys Val Cys Asp Arg Val Phe Tyr Arg Leu Asp Asn Leu Arg Ser His Leu Lys Gln His

\#6 Iyr Met Cys His Thr Cys Lys Asn Cys Phe Tyr Ser Leu Pro Thr Leu Asn Ile His Ile Arg Thr His

\#7 Phe Asp Cys Asp Leu Cys Asp Lys Lys phe Ser Ala Leu Val Ala Leu Lys Lys His Arg Arg Tyr His

\#8 Iyr Ser Cys Thr Val Cys Asn Gln Ala Phe Ala Val Lys Glu Val Leu Asn Arg His Met Lys Arg his

\#9 His Lys Cys Asp Glu Cys Gly Lys Ser Phe Ile Arg Ala Thr Gln Leu Arg Thr His Ser Lys Thr His

\#10 Phe Pro Cys Glu Gln Cys Asp Glu Lys Phe Lys Thr Glu Lys Gln Leu Glu Arg His Val Lys Thr His

\#11 Phe Ser Cys Ala Glu Cys Lys Arg Asn Phe Arg Thr Pro Ala Leu Leu Lys Glu His Met Asp Glu Gly Lys His

\#12 Thr Asp Cys Ala Ile Cys Asp Lys Asn Phe Asp Ser Ser Asp Thr Leu Arg Arg His Ile Arg Thr Val His
\end{abstract}

\title{
Consensus Phe Xaa Cys Xaa Xaa Cys Xaa Xaa Xaa Phe Xaa Xaa Xaa Xaa Xaa Leu Xaa Xaa His Xaa Xaa Xaa Xaa His Tyr
}

Figure 7. Amino acid structure of the $\mathrm{Zn}$ finger domains of the $s u(H w)$-encoded protein. The protein sequences of the different $\mathrm{Zn}$ finger regions contained in the $s u(H W)$ protein are numbered $1-12$, starting at the amino-terminal end of the protein. Also shown is a consensus sequence derived from similar regions found in other organisms. Residues conserved with respect to the consensus sequence have been underlined.

domain. This type of structure has been found in some nucleic-acid-binding proteins. For example, TFIIIA, a polymerase III transcription factor that interacts with both DNA and RNA contains nine copies of the $\mathrm{Zn}$ finger domain (Miller et al. 1985). Other proteins in which this type of structure has been found include the Drosophila Krüppel (Rosenberg et al. 1986), hunchback (Tautz et al. 1987), and serendipity (Vincent et al. 1985) gene products, the yeast ADR1 (Blumberg et al. 1987) and GAL4 (Johnston 1987) proteins, and the human estrogen and glucocorticoid receptors (Giguere et al. 1986; Green and Chambon 1987). The structure of the different fingers present in the $s u(\mathrm{Hw})$ protein is well conserved with respect to the proposed consensus sequence for this type of functional domain. The few deviations from the consensus have also been found in other fingers shown to be functional, suggesting that all 12 fingers present in the $s u(H w)$ protein should be able to bind DNA.

In addition, the $s u(H w)$-encoded product contains a very acidic region (48\% Asp and Glu) located upstream of the first finger domain. Similar acidic tracts have been found in the GCN4 and GAL4 proteins of yeast (Hope and Struhl 1986; Ma and Ptashne 1987), which are transcriptional activators of genes encoding proteins involved in amino acid biosynthesis and galactose catabolism, respectively. The acidic domain of these two proteins is not involved in DNA binding but rather in transcriptional activation via protein-protein interactions, presumably with a TATA-binding protein or RNA polymerase II (Hope et al. 1988).

The presence of this modular structure, acidic domain and $\mathrm{Zn}$ finger motifs, in the $s u(H w)$ product suggests that this protein might be a transcription factor involved in the control of the expression of normal cellular genes. In addition, the existence of these two structural characteristics correlates with previously proposed roles for the $\mathrm{su}(\mathrm{Hw})$ protein to explain the mechanism of gypsy mu- tagenesis and the reversion of the gypsy-induced phenotypes by homozygous mutations at the $s u(H w)$ locus. We have shown that levels of gypsy RNA are 25-fold lower in $s u(H w)^{-}$mutants as compared to wild type and have suggested that the mutagenicity of the gypsy element might be related to the $s u(\mathrm{HW})$-dependent transcriptional activation of this element during the pupal stages of development (Parkhurst and Corces 1985, 1986a). The case we have studied in most detail is that of the $y^{2}$ allele, in which the insertion of gypsy at -700 bp from the start of transcription of the yellow RNA causes an adult-specific phenotype that results in wildtype colored bristles but mutant wing blades and body cuticle (Biessmann 1985; Chia et al. 1986; Geyer et al. 1986; Parkhurst and Corces 1986a). To explain the temporal and spatial restrictions of this phenotype and its reversibility by $s u(H w)$ mutations, we have proposed two possible complementary and overlapping explanations. The tissue-specific $y^{2}$ phenotype might be a consequence of changes in the chromatin structure of the yellow locus due to the transcriptional activation of the gypsy element during pupal development in the affected tissues, when yellow expression is necessary for proper coloration of adult cuticular structures (Parkhurst and Corces 1986b). Alternatively, transcription of gypsy might not be necessary per se, and it is merely the binding of the $s u(\mathrm{Hw})$-encoded protein to particular sequences located in the central portion of the gypsy element that affects the proper interaction of tissue-specific transcriptional enhancers with the yellow promoter and results in mutant phenotype in these particular tissues (Geyer and Corces 1987; Geyer et al. 1988). Both hypotheses require the interaction of the $s u(\mathrm{HW})$ protein with DNA sequences located in the gypsy element, a condition supported by the presence of $\mathrm{Zn}$ finger domains in the predicted amino acid sequence of the $s u(H w)$ product.

The cloning of the $s u(\mathrm{Hw})$ locus will afford the isola- 
tion of the encoded protein and the study of its interaction in vitro with gypsy DNA. From this type of analysis we hope to gain further understanding of the mechanisms by which transposable elements induce mutant phenotypes and how these can be enhanced or reversed by second site mutations at modifier loci.

\section{Materials and methods}

\section{Isolation and maintenance of Drosophila strains}

Fly stocks were maintained at $22.5^{\circ} \mathrm{C}$ and $65 \%$ relative humidity. The $s u(H w)^{B}$ and $s u(H w)^{C}$ alleles were obtained by crossing $b x^{34 e}$ males, which had been irradiated with $\gamma$-rays (3000 rads), with females of the genotype TM3, su(Hw) ${ }^{2} \mathrm{Sb}$ $b x^{34 e} / T M 6, s u(H w)^{f} U b x^{P 15} e^{s}$, and the progeny were scored for $b^{+}$phenotype. Some su(Hw) alleles used in this study, such as $s u(H w)^{69 k}$ and $s u(H w)^{2}$, are female sterile and are maintained as balanced stocks over the chromosome TM6, su(Hw)f. These two particular alleles show very low viability as homozygotes, probably due to the accumulation of lethal mutations in these chromosomes that have no effects in the balanced stocks. This is evidenced by the fact that these alleles exhibit high viability when compounded with a deficiency of the $s u(\mathrm{Hw})$ region.

\section{Isolation and enzymology of nucleic acids}

Isolation of plasmid DNA, construction and screening of $\lambda$ libraries, and DNA labeling and enzymology were carried out by standard procedures (Maniatis et al. 1982). Genomic DNA from Drosophila adults was prepared as described previously (Parkhurst and Corces 1985). Total RNA was isolated from synchronously developing Drosophila cultures by homogenization in $4 \mathrm{M}$ guanidine isothiocyanate, $0.2 \% \mathrm{~N}$-lauroyl sarcosine, $150 \mathrm{~mm}$ mercaptoethanol, $12.5 \mathrm{~mm}$ EDTA, and $50 \mathrm{~mm}$ Tris-hydrochloride ( $\mathrm{pH} 7.5$ ), followed by phenol extraction and ethanol precipitation (Parkhurst and Corces 1985). Poly(A) ${ }^{+}$RNA was selected by chromatography on oligo(dT)-cellulose (Aviv and Leder 1972). Ovaries for RNA preparation were dissected from mature adult females in $130 \mathrm{mM} \mathrm{NaCl}, 5 \mathrm{~mm} \mathrm{KCl}, 2 \mathrm{mM} \mathrm{CaCl}_{2}$, and $10 \mathrm{~mm}$ HEPES ( $\mathrm{pH}$ 6.9). The tissue was then homogenized in $10 \mathrm{~mm}$ EDTA, $100 \mathrm{~mm} \mathrm{NaCl}, 0.5 \%$ SDS, $250 \mu \mathrm{g} / \mathrm{ml}$ proteinase $\mathrm{K}$, and $50 \mathrm{mM}$ Tris-hydrochloride (pH 7.5), phenol extracted three times, and ethanol-precipitated (Parks et al. 1986). Southern and Northern analysis was done as previously described (Parkhurst and Corces 1985). DNA sequence analysis was performed according to Maxam and Gilbert 1980.

P-element-mediated transformation was carried out as described by Rubin and Spradling (1982), using the white gene as a selectable marker in the CaSpeR vector (Pirrotta et al. 1985). In situ hybridizations to polytene chromosomes were done by the method of Pardue and Gall (1975).

\section{Acknowledgments}

We would like to thank Dr. M. Green for many fruitful discussions during the preparation of this manuscript and Dr. A. Spradling for support and advice. The mutagenesis experiments leading to the isolation of $s u(H w)^{B}$ and $s u(H w)^{C}$ were carried out by Robert Coyne during his stay in the Department of Biochemistry and Molecular Biology at Harvard University. We would like to thank Dr. M. Meselson for his constant encouragement and support throughout those studies. We also thank Drs. M. Levine for the gift of $\lambda S 63$, V. Pirrotta for the CaSpeR vector, M. Peifer, W. Bender, and E. Grell for several su(Hw) alleles and their parental stocks. A. Greenleaf and colleagues for unpublished mapping data, S. Parks for protocols to prepare ovarian RNA, and T. Kornberg and L. Kauvar for cDNA libraries. S.M.P. would like to thank Drs. Suki Parks, Ward Odenwald, Brian Mozer, and colleagues in the Hopkins/Carnegie fly groups for valuable suggestions, sharing unpublished data, and moral support during the course of these studies. The work reported here was supported by U.S. Public Health Service grant GM-35463, and American Cancer Society grant NP-546.

\section{Note}

Sequence data described in this paper have been submitted to the EMBL/GenBank Data Libraries under accession number Y00228.

\section{References}

Aviv, H. and P. Leder. 1972. Purification of biologically active globin messenger RNA by chromatography on oligothymidylic acid-cellulose. Proc. Natl. Acad. Sci. 69: 1408-1412.

Berg, J. 1988. Proposed structure for the zinc-binding domains from transcription factor IIIA and related proteins. Proc. Natl. Acad. Sci. 85: 99-102.

Biessman, H. 1985. Molecular analysis of the yellow gene $(y)$ region of Drosophila melanogaster. Proc. Natl. Acad. Sci. 82: 7369-7373.

Blumberg, H., A. Eisen, A. Sledziewski, D. Bader, and E.T. Young. 1987. Two zinc fingers of a yeast regulatory protein shown by genetic evidence to be essential for its function. Nature 328: 443-445.

Chang, D.-Y., B. Wisely, S.-M. Huang, and R.A. Volker. 1986. Molecular cloning of suppressor of sable, a Drosophila melanogaster transposon-mediated suppressor. Mol. Cell. Biol. 6: $1520-1528$.

Chia, W., G. Howes, M. Martin, Y.B. Meng, K. Moses, and S. Tsubota. 1986. Molecular analysis of the yellow locus of Drosophila. EMBO I. 5: 3597-3605.

Chou, T.-B., Z. Zachar, and P.M. Bingham. 1987. Developmental expression of a regulatory gene is programmed at the level of splicing. EMBO I. 6: 4095-4104.

Clark-Adams, C.D. and F. Winston. 1987. The SPT6 gene is essential for growth and is required for $\delta$-mediated transcription in Saccharomyces cerevisiae. Mol. Cell. Biol. 7: 679686.

Fassler, J.S. and F. Winston. 1988. Isolation and analysis of a novel class of suppressors of Ty insertion mutations in Saccharomyces cerevisiae. Genetics 118: 203-212.

Geyer, P.K. and V.G. Corces. 1987. Separate regulatory elements are responsible for the complex pattern of tissue-specific and developmental transcription of the yellow locus in Drosophila melanogaster. Genes Dev. 1: 996-1004.

Geyer, P.K., M.M. Green, and V.G. Corces. 1988. Reversion of a gypsy-induced mutation at the yellow $(y)$ locus of Drosophila melanogaster is associated with the insertion of a newly defined transposable element. Proc. Natl. Acad. Sci. 85: 3938-3942.

Geyer, P.K., C. Spana, and V.G. Corces. 1986. On the molecular mechanism of gypsy-induced mutations at the yellow locus of Drosophila melanogaster. EMBO J. 5: 2657-2662.

Gigurere, V., S.M. Hollenberg, M.G. Rosenfeld, and R.M. Evans. 1986. Functional domains of the human glucocorticoid receptor. Cell 41: 645-652.

Green, M.M. 1955. Phenotypic variations and pseudoallelism at 
the forked locus in Drosophila melanogaster. Proc. Natl. Acad. Sci. 41: 375-379.

1959. Spatial and functional properties of pseudoalleles at the white locus in Drosophila melanogaster. Heredity 13: $303-315$

Green, S. and P. Chambon. 1987. Oestradiol induction of a glucocorticoid-responsive gene by a chimaeric receptor. Nature 325: 75-78.

Hope, I.A. and K. Struhl. 1986. Functional dissection of a eukaryotic transcriptional activator protein, GCN4 of yeast. Cell 46: 885-894.

Hope, I.A., S. Mahadevan, and K. Struhl. 1988. Structural and functional characterization of the short acidic transcriptional activation region of yeast GCN4 protein. Nature 333: $635-640$.

Johnston, M. 1987. Genetic evidence that zinc is an essential co-factor in the DNA binding domain of GAL4 protein. $\mathrm{Na}$ ture 328: 353-355.

Klug, A. and D. Rhodes. 1987. 'Zinc fingers': A novel protein motif for nucleic acid recognition. Trends Biochem. Sci. 12: 464-469.

Kubli, E. 1986. Molecular mechanisms of suppression in Drosophila. Trends Genet. 2: 204-209.

Levis, R., K. O'Hare, and G.M. Rubin. 1984. Effects of transposable element insertions on RNA encoded by the white gene of Drosophila. Cell 38: 471-481.

Lewis, E.B. 1981. Developmental genetics of the bithorax complex in Drosophila. In Developmental biology using purified genes (ed. D.D. Brown and C.F. Fox), pp. 189-208. Academic Press, New York.

Lindsley, D.L. and E.H. Grell. 1968. Genetic variations of Drosophila melanogaster. Carnegie Inst. Wash. Publication No. 627.

Ma, J. and M. Ptashne. 1987. Deletion analysis of GAL4 defines two transcriptional activating segments. Cell 48: 847-853.

Maniatis, T., E.F. Fritsch, and J. Sambrook. 1982. Molecular cloning: A laboratory manual. Cold Spring Harbor Laboratory, Cold Spring Harbor, New York.

Maxam, A.M. and W. Gilbert. 1980. Sequencing end-labeled DNA with base-specific chemical cleavages. Methods Enzymol. 65: 499-560.

Melton, D.A., P.A. Krieg, M.R. Rebagliati, T. Maniatis, K. Zinn, and M.R. Green. 1984. Efficient in vitro synthesis of biologically active RNA and RNA hybridization probes from plasmids containing a bacteriophage SP6 promoter. Nucleic Acids Res. 12: 7035-7056.

Miller, J., A.D. McLachlan, and A. Klug. 1985. Repetitive zincbinding domains in the protein transcription factor IIIA from Xenopus oocytes. EMBO J. 4: 1609-1614.

Modolell, J., W. Bender, and M. Meselson. 1983. D. melanogaster mutations suppressible by the suppressor of Hairy. wing are insertions of a $7.3 \mathrm{~kb}$ mobile element. Proc. Natl. Acad. Sci. 80: 1678-1682.

Mount, S.M., M.M. Green, and G.M. Rubin. 1988. Partial revertants of the transposable element-associated suppressible allele white-apricot in Drosophila melanogaster: Structures and responsiveness to genetic modifiers. Genetics 118: $221-234$.

Mozer, B., R. Marlor, S. Parkhurst, and V. Corces. 1985. Characterization and developmental expression of a Drosophila ras oncogene. Mol. Cell. Biol. 5: 885-889.

Pardue, M.L. and J.G. Gall. 1975. Nucleic acid hybridization to the DNA of cytological preparations. Methods Cell Biol. 101: $1-17$.

Parkhurst, S.M. and V.G. Corces. 1985. forked, gypsys, and suppressors in Drosophila. Cell 41: 429-437. 1986a. Interactions among the gypsy transposable element and the yellow and the suppressor of Hairy wing loci in Drosophila melanogaster. Mol. Cell. Biol. 6: 47-53.

- 1986b. Retroviral elements and suppressor genes in Drosophila. BioEssays 5: 52-57.

Parks, S., B. Wakimoto, and A. Spradling. 1986. Amplification and expression of an X-linked cluster of Drosophila chorion genes. Dev. Biol. 117: 294-305.

Pirrotta, V., H. Steller, and M.P. Bozzetti. 1985. Multiple upstream regulatory elements control the expression of the Drosophila white gene. EMBO /. 4: 3501-3508.

Poole, S.J., L.M. Kauvar, B. Drees, and T. Kornberg. 1985. The engrailed locus of Drosophila: Structural analysis of an embryonic transcript. Cell 40: 37-43.

Roeder, G.S. and G.R. Fink. 1983. Transposable elements in yeast. In Mobile genetic elements (ed. J.A. Shapiro), pp. 300-328. Academic Press, New York.

Rosenberg, U.B., C. Schroder, A. Preiss, A. Kienlin, S. Cote, I. Riede, and H. Jackle. 1986. Structural homology of the product of the Drosophila Krüppel gene with Xenopus transcription factor IIIA. Nature 319: 336-339.

Rubin, G.M. 1983. Dispersed repetitive DNAs in Drosophila. In Mobile genetic elements (ed. J.A. Shapiro) pp. 329-361. Academic Press, New York.

Rubin, G.M. and A.C. Spradling. 1982. Genetic transformation of Drosophila with transposable element vectors. Science 218: $348-353$.

Rutledge, B.J., M.A. Mortin, E. Schwarz, D. Thierry-Mieg, and M. Meselson. 1988. Genetic interactions of modifier genes and modifiable alleles in Drosophila melanogaster. Genetics 119: 391-397.

Schalet, A. 1970. Some observations on the proximal euchromatic-heterochromatic region of the $\mathrm{X}$ chromosome in Drosophila melanogaster. Genen Phaenen 14: 16-17.

Searles, L. and R.A. Voelker. 1986. Molecular characterization of the Drosophila vermilion locus and its suppressible alleles. Proc. Natl. Acad. Sci. 83: 404-408.

Snyder, R.D. and P.D. Smith. 1976. The suppressor of forked mutation in Drosophila melanogaster: Interactions with the lozenge gene. Biochem. Genet. 14: 611-617.

Tautz, D., R. Lehman, H. Schnurch, R. Schuh, E. Seifert, A. Kienlin, K. Jones, and H. Jackle. Finger protein of novel structure encoded by hunchback, a second member of the gap class of Drosophila segmentation genes. Nature 327: 383-389.

Vincent, A., H.V. Colot, and M. Rosbash. 1985. Sequence and structure of the serendipity locus of Drosophila melanogaster. J. Mol. Biol. 185: 146-166.

Winston, F., K.F. Durbin, and G.R. Fink. 1984a. The SPT3 gene is required for normal transcription of Ty elements in $S$. cerevisiae. Cell 39: 675-682.

Winston, F., D.T. Chaleff, B. Valent, and G.R. Fink. 1984b. Mutations affecting Ty-mediated expression of the HIS4 gene in Saccharomyces cerevisiae. Genetics 107: 179-197.

Winston, F., C. Dollard, E.A. Malone, J. Clare, J. Kapakos, P. Farabaugh, and P. Minehart. 1987. Three genes are required for trans-activation of Ty transcription in yeast. Genetics 115: 649-656.

Zachar, Z., T.-B. Chou, and P.M. Bingham. 1987. Evidence that a regulatory gene autoregulates splicing of its transcript. EMBO I. 6: 4105-4111.

Zachar, Z., D. Davison, D. Garza, and P.M. Bingham. 1985. A detailed developmental and structural study of the transcriptional effects of insertion of the copia transposon into the white locus of Drosophila melanogaster. Genetics 111: $495-515$. 


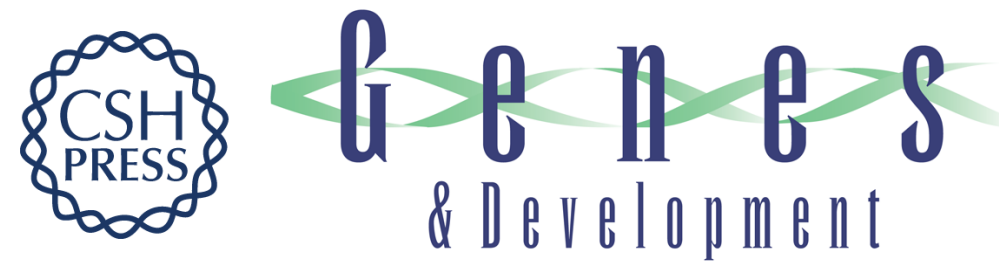

\section{The Drosophila su(Hw) gene, which controls the phenotypic effect of the gypsy transposable element, encodes a putative DNA-binding protein.}

S M Parkhurst, D A Harrison, M P Remington, et al.

Genes Dev. 1988, 2:

Access the most recent version at doi:10.1101/gad.2.10.1205

References This article cites 48 articles, 19 of which can be accessed free at:

http://genesdev.cshlp.org/content/2/10/1205.full.html\#ref-list-1

License

Email Alerting Service

Receive free email alerts when new articles cite this article - sign up in the box at the top right corner of the article or click here.

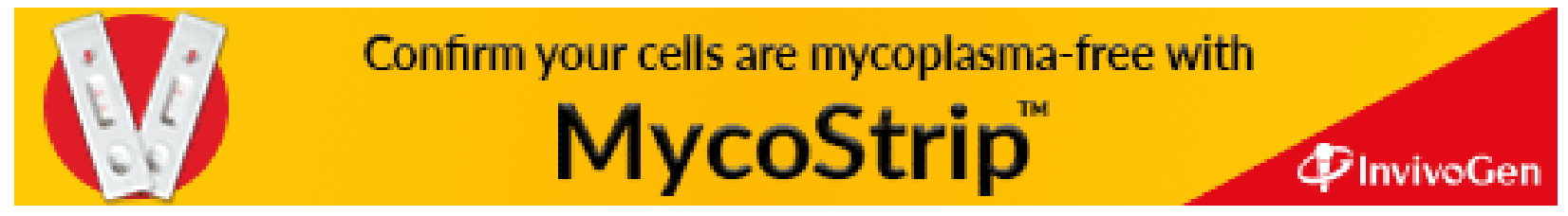

